\title{
Transparent reporting of studies relevant to physical therapy practice
}

\author{
Como escrever de forma transparente artigos científicos relevantes para a \\ prática da Fisioterapia
}

\author{
Leonardo O. P. Costa',2, Chris G. Maher', Alexandre D. Lopes', Marcos A. de Noronha³, Lucíola C. M. Costa',2
}

\begin{abstract}
Background: There was a clear grow, in the last 2 decades, of up to 6 fold in scientific articles that are directly relevant to physical therapy practice. However, along with this fast grow; little attention has been given to transparency when reporting research methods and results. More recently, groups of researchers around the world have made successful attempts to address this issue by creating guidelines that will help researchers not only on the preparation of manuscripts but also on making sure that important details related to design and methodology are controlled and reported. Objective: To present four specific reporting guidelines, which are best known as "statements". Discussion: A network named EQUATOR (Enhancing the Quality and Transparency of Health Research) was created with the main mission of providing basic principles for responsible and transparent reporting. The EQUATOR network encompasses, among others, the CONSORT statement which is related to randomized controlled trials; the PRISMA statement, which is related to systematic reviews and meta-analysis; the STROBE Statement, which is related to observational studies; and the STARD statement, which is related to reporting of accuracy of diagnostic tests. Some journals have recommended the use of these statements, while in others their use is mandatory. The goal of the use of these statements by journals is to guarantee fast decisions regarding publication and the best possible quality of reporting. Ultimately, it will help readers, including physical therapists, to make better decisions in clinical practice.
\end{abstract}

Keywords: physical therapy; bias; guideline; editorial policies.

\section{Resumo}

Contextualização: Nas últimas duas décadas, ocorreu um nítido crescimento, de até seis vezes, do número de artigos científicos que são diretamente relevantes para a prática da Fisioterapia. No entanto, junto com esse rápido crescimento, tem-se dado pouca atenção à transparência de como são descritos os métodos e os resultados desses estudos. Mais recentemente, grupos de pesquisadores ao redor do mundo têm feito tentativas bem sucedidas para resolver esse problema por meio da criação de diretrizes que auxiliam os pesquisadores não apenas na preparação dos manuscritos, mas também garantem que detalhes importantes relacionados ao delineamento e à metodologia do estudo sejam devidamente descritos. Objetivo: Apresentar quatro diretrizes específicas para descrever artigos científicos, que são mais conhecidas como "recomendações". Discussão: Uma rede denominada EQUATOR (Melhorando a Qualidade e a Transparência da Pesquisa em Saúde) foi criada com a missão principal de fornecer os princípios básicos de como escrever artigos científicos de forma clara e fidedigna. A rede EQUATOR engloba, entre outros, as recomendações CONSORT, que estão relacionadas com estudos controlados aleatorizados; as recomendações PRISMA, que estão relacionadas com revisões sistemáticas e meta-análises; as recomendações STROBE, que estão relacionadas com estudos observacionais e as recomendações STARD, que estão relacionadas com a descrição de estudos referentes à precisão de testes diagnósticos. Algumas revistas científicas têm apoiado a utilização dessas recomendações, enquanto, em outras revistas, o uso é obrigatório. O objetivo da utilização dessas recomendações pelas revistas científicas é garantir a tomada rápida de decisões relativas à publicação e à melhor qualidade possível de como o artigo científico foi reportado. Em última análise, essas recomendações irão ajudar os leitores, incluindo fisioterapeutas, a tomarem melhores decisões na prática clínica.

Palavras-chave: fisioterapia; viés; diretrizes; políticas editoriais. 


\section{Introduction $: \therefore$.}

It is unquestionable that the amount of research relevant to physical therapy practice has vastly increased over the last two decades. As an example, the number of randomized controlled trials evaluating physical therapy interventions has grown exponentially in this period, i.e. there were 1,925 trials in 1990'; 5,301 in $2000^{1}$ and 15,293 in May $2011^{2}$ ( figure 1). Although the number of randomized controlled trials in physical therapy is growing rapidly, it is important to highlight that the methodological quality of these trials is very heterogeneous which complicates the decision making process for physical therapists around the world. This is because results from methodologically flawed randomized trials are more likely to contain biased or misleading estimates of treatment effects ${ }^{3}$.

The methodological quality of systematic reviews is also very heterogeneous and this heterogeneity can limit the interpretation and clinical application of the results from these reviews. There is evidence that Cochrane systematic reviews related to physical therapy interventions have better methodological quality when compared to non-Cochrane reviews ${ }^{4}$. The Cochrane Collaboration has specific guidelines ${ }^{5}$ to help authors to design, conduct and report their reviews, making their reviews more comprehensive, accurate and easier to read. Accordingly, physical therapists should place more confidence in the results from a Cochrane systematic review than the results from a non-Cochrane review. It is important to state that this finding is consistent with other fields such as dermatology $y^{6}$, maternal medicine ${ }^{7}$ and general medicine ${ }^{8}$.

Other types of research that are relevant to physical therapy are observational studies (i.e., cohort studies ${ }^{9}$, cross-sectional studies ${ }^{10}$ and case-control studies $\left.{ }^{11}\right)$ as well as diagnostic accuracy studies $^{12}$. To our knowledge, there are no studies that have evaluated the methodological quality and reporting of

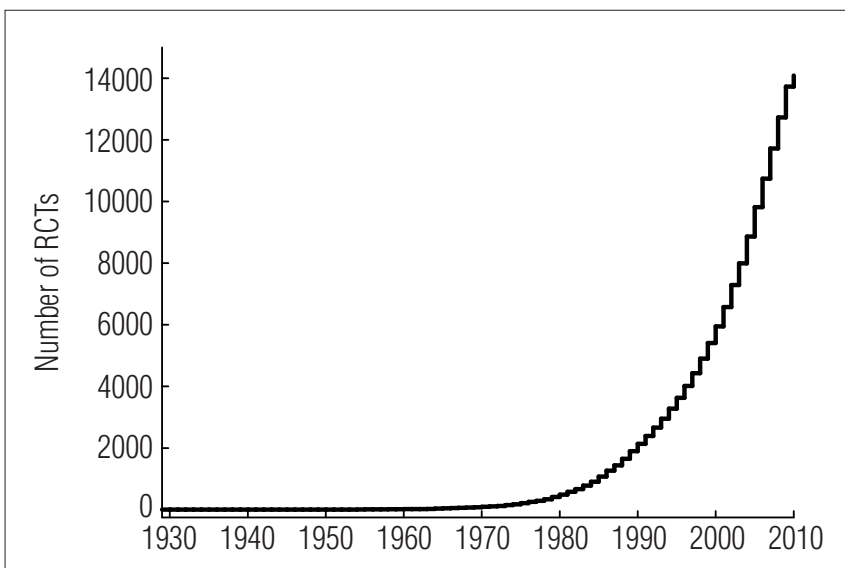

Figure 1. Cumulative frequency of the number of randomized controlled trials (RCTs) relevant to physical therapy by decade. these types of studies in the physical therapy field, however, it is likely that they would have similar problems with reporting as has been found in other health-related fields ${ }^{13,14}$.

\section{Poor quality or poor reporting?}

Once a study has been completed the only way to judge the quality of the design and conduct of the study is by appraisal of the published report of the study. Unfortunately not all manuscripts provide the necessary information that enables clinicians and researchers to confidently appraise the methodological quality of a study. In many cases, some studies are scored low on methodological scales, because many critical methodological criteria cannot be evaluated due to poor reporting ${ }^{15,16}$. A recent systematic review on this topic ${ }^{17}$ observed that although there is a trend for improvement in the quality of reporting of randomized controlled trials over time, the current quality of reporting is still below an acceptable level ${ }^{17}$, therefore authors, journal editors and reviewers are still in need of more guidance regarding high quality study reporting. Interestingly this issue has been discussed by researchers for quite a long time, for example, an important paper published in 1982 in the New England Journal of Medicine stated that "editors could greatly improve the reporting of clinical trials by providing authors with a list of items that they expected to be strictly reported"18. To meet this need the EQUATOR Network ${ }^{19}$, an international group of researchers, has developed reporting checklists for most types of studies.

\section{The EQUATOR Network}

The EQUATOR (Enhancing the Quality and Transparency of Health Research) is an international initiative aimed to promote better reporting of health research. The main mission of this organization is to provide and to disseminate the basic principles for responsible and transparent reporting as well as the implementation of these principles into rese$\operatorname{arch}^{20}$. The EQUATOR initiative believes that some important issues related to poor reporting such as selective reporting (i.e. omitting information from some outcomes of the study), omission of crucial information from methods, results and possible harms, confusing presentation of the results, poor description of the interventions and poorly written abstracts can be addressed by using the recommendations from the statements developed by their group ${ }^{20}$. All documents from the EQUATOR network, including articles, statements, tutorials, web-based workshops and checklists are freely available at the URL: http://www.equator-network.org/home/. 


\section{Objective $: \because 8$}

The current article will briefly present four EQUATOR statements: 1) The CONSORT (Consolidated Standards of Reporting Trials) statement, 2) The PRISMA (Preferred Reporting Items for Systematic Reviews and Meta-Analyses) statement, 3) The STROBE (STrengthening the Reporting of OBservational studies in Epidemiology) statement and 4) The STARD (STAndards for the Reporting of Diagnostic accuracy studies) statement.

\section{The CONSORT Statement}

The CONSORT Statement is an evidence-based, minimum set of recommendations for reporting randomized controlled trials $^{21}$. There are extensions of the statement that provide additional guidance on specific types of randomized trials based upon the design (e.g., cluster trials, pragmatic trials) or the treatment tested (e.g. non-pharmacological trials, herbal medicine trials, acupuncture trials). The CONSORT Statement offers a standard way for authors to prepare reports of trial findings, facilitating their complete and transparent reporting which will aid their critical appraisal and interpretation. The CONSORT Statement includes a flow diagram, a 25-item checklist and some brief descriptive text elaborating on the meaning of each item. The checklist items focus on reporting how the trial was designed, analysed, and interpreted; and the flow diagram displays the progress of all participants through the trial. The first version of the CONSORT Statement was published in $1996^{22}$ and the last update took place in $2010^{23}$. The Revista Brasileira de Fisioterapia/Brazilian Journal of Physical Therapy (RBF/BJPT) recently endorsed the use of the CONSORT Statement for all trials published since September $2010^{24}$ and it is strongly recommended that authors of the RBF/BJPT should check for CONSORT updates prior to the writing and submission of randomized controlled trials. All documents related to the CONSORT Statement, including the explanation of the checklist items, templates for the CONSORT flow diagram and the CONSORT Checklist itself can be found at the URL: http://www.consort-statement.org/.

\section{The CONSORT Checklist}

Whenever an author writes a randomized controlled trial for a journal such as the RBF/BJPT, the CONSORT checklist can be very useful as it will help authors to cover all relevant aspects related to the internal and external validity of a trial. During the submission process authors are required to complete the CONSORT Checklist by noting which items were covered or not and on which page of the manuscript the information can be located. The 25-item 2010 CONSORT Checklist can be downloaded from the URL: http://www.consort-statement. org/consort-statement/overview0/\#checklist .

\section{The PRISMA Statement}

The PRISMA statement is a set of items to help authors properly report a systematic review and/or a meta analysis. For those familiar with reporting guidelines, the PRISMA statement is the updated version of the QUORUM (QUality Of Reporting Of Meta-analyses) Statement ${ }^{25}$. Although the PRISMA statement was primarily developed for the reporting of systematic reviews of interventions, this statement has been widely used in systematic reviews of measurement properties $^{26}$, prognosis $^{27}$, diagnosis ${ }^{28}$, cross-cultural adaptations ${ }^{29}$ and other $\mathrm{s}^{30}$. Similarly to the CONSORT statement, although the PRISMA statement is not designed to assess the methodological quality of systematic reviews, it is possible to use it for critical appraisal of systematic reviews and/or metaanalysis. The PRISMA statement includes a 27-item checklist and a four-phase flow chart along with an explanation of each checklist item, including examples ${ }^{31}$. These 27 items will guide authors of systematic reviews on what information should be clearly reported in the manuscript, including specific instructions for the title, abstract, methods, results and funding. All documents related to the PRISMA Statement, including the explanation of the items, templates for the PRISMA flow diagram and the PRISMA Checklist can be found at the URL: http://www.prisma-statement.org/index.htm.

\section{The STROBE Statement}

A recent survey of four major rehabilitation journals ${ }^{32}$ indicated that around a third of the total amount of publications in the rehabilitation field are observational studies. Observational studies should be understood as an umbrella term for cross sectional, case-control and cohort studies ${ }^{33}$. Similarly to randomized controlled trials and systematic reviews, observational studies have also been poorly reported ${ }^{14}$. In order to address this issue of inadequate reporting of observational studies, a group of methodologists, journal editors and researchers developed the STROBE Statement ${ }^{34}$. This statement has 22 items; 18 common to all three study designs; and 4 specifically developed for cohort, case-control or cross sectional studies. The STROBE statement is a fairly recent development and, like the CONSORT statement, is likely to be updated in the future as more is learnt about the reporting of observational studies. Therefore we recommend authors to check for updates thorough the STROBE website (http://www.strobe-statement. org/) prior to writing and submitting manuscripts to journals. 
This website also contains all documents needed for a better understanding of this statement, including articles and the STROBE checklist.

\section{The STARD Statement}

Physical Therapists need an understanding on the accuracy of diagnostic tests so that they can interpret the results of their own clinical assessments or interpret exams prescribed by medical colleagues. The diagnostic field is very dynamic, with new diagnostic tools being frequently developed, therefore it is crucial to understand the diagnostic accuracy of these new tests prior to their clinical use. Physical therapists can make wrong clinical decisions if they fail to consider the accuracy of a diagnostic test, or fail to recognise biased results from poorly designed and reported diagnostic accuracy studies. This issue was discussed by the Cochrane Diagnostic and Screening Test Methods Working Group during the 1999 Cochrane Colloquium, and this group of researchers decided to address the issue with a similar approach to that used by the CONSORT group. The diagnostic researchers developed a 25-item checklist called the Standard for Reporting Diagnostic Accuracy (STARD) Statement ${ }^{35}$. The STARD statement has been endorsed by hundreds of journals and although the quality of diagnostic accuracy is improving, there is still room for further improvement in this field ${ }^{36}$. All documents related to the STARD initiative can be found at the following link: http://www.stard-statement.org/.

\section{Discussion : :}

We aimed to present four important statements that are very useful in helping authors to better report studies that are commonly read by physical therapists. Well-designed and conducted studies are the goal of researchers because they best provide accurate and precise information to assist clinical decision making. Complete and accurate reporting of research studies is equally important because this enables readers to judge the methodological quality of a study. We strongly believe that if all physical therapy journals endorse the use of these statements, the quality of reporting will increase substantially in a short period of time.

We are aware that the endorsement of these statements is not only a matter of including this information on the "instructions to authors" section; there is a substantial amount of data showing that although the quality of reporting has been improving, the speed of improvement in reporting, as well as in methodological quality, is very slow even in journals that have already endorsed these statements ${ }^{17,36,37}$. To address this issue, journal editors should not only request that authors follow the recommendations of the statements, but also prepare their reviewers and administrative staff to check if the authors followed the recommendations from the statements. This could be facilitated by asking authors to include the completed checklist along with the manuscript during the submission process.

The use of these statements can benefit authors, journal reviewers and readers of physical therapy journals. From the author's perspective, these statements have the potential to ease the writing of manuscripts as these minimum set of recommendations are likely to guarantee that all relevant aspects of research design will be covered. Journal reviewers can use the statements to check if all necessary information from submitted articles was presented or not, which can guide their decision to accept the manuscript, or provide feedback to the author on how to improve their manuscript. Finally and most importantly, from the reader's point of view, articles that are written based on the recommendations from these statements are easier to interpret and appraise, and ultimately, they will help readers to make better decisions in clinical practice.

\section{Acknowledgements : :}

To the Fundação de Amparo a Pesquisa do Estado de São Paulo (FAPESP), Brazil, to the Australian Research Council, Australia and to the University of Sydney, Australia.

\section{References}

1. Maher CG, Moseley AM, Sherrington C, Elkins MR, Herbert RD. A description of the trials, reviews, and practice guidelines indexed in the PEDro database. Phys Ther. 2008;88(9): 1068-77.

2. PEDro. PEDro access statistics. 2011 [cited 2011 10/05]; Accessed 10/05/2011. Available from: www.pedro.org.au.

3. Herbert R, Jamtvedt G, Mead J, Hagen KB. Practical Evidence-Based Physiotherapy. London: Elsevier's Health Sciences; 2005.
4. Moseley AM, Elkins MR, Herbert RD, Maher CG, Sherrington C. Cochrane reviews used more rigorous methods than non-Cochrane reviews: survey of systematic reviews in physiotherapy. $J$ Clin Epidemiol. 2009;62(10):1021-30.

5. Higgins JPT, Green S. Cochrane Handbook for Systematic Reviews of Interventions Version 5.0.0 The Cochrane Collaboration. Available from http://www.cochrane.org/resources/handbook; 2008.

6. Collier A, Heilig L, Schilling L, Williams H, Dellavalle RP. Cochrane Skin Group systematic 
reviews are more methodologically rigorous than other systematic reviews in dermatology. $\mathrm{Br} \mathrm{J}$ Dermatol. 2006;155(6):1230-5.

7. Sheikh L, Johnston S, Thangaratinam S, Kilby MD, Khan KS. A review of the methodological features of systematic reviews in maternal medicine. BMC Med. 2007:5:10.

8. Jadad AR, Cook DJ, Jones A, Klassen TP, Tugwell P, Moher M, et al. Methodology and reports of systematic reviews and meta-analyses: a comparison of Cochrane reviews with articles published in paper-based journals. JAMA. 1998;280(3):278-80.

9. Costa LCM, Maher CG, McAuley JH, Hancock MJ, Herbert RD, Refshauge KM, et al. Prognosis for patients with chronic low back pain: inception cohort study. BMJ. 2009;339:b3829.

10. Stanton TR, Fritz JM, Hancock MJ, Latimer J, Maher CG, Wand BM, et al. Evaluation of a treatment-based classification algorithm for low back pain: a cross-sectional study. Phys Ther. 2011;91(4):496-509

11. Pinto RZ, Ferreira PH, Franco MR, Ferreira ML, Ferreira MC, Teixeira-Salmela LF, et al. Effect of 2 lumbar spine postures on transversus abdominis muscle thickness during a voluntary contraction in people with and without low back pain. J Manipulative Physiol Ther. 2011;34(3):164-72.

12. Henschke N, Maher CG, Refshauge KM. A systematic review identifies five "red flags" to screen for vertebral fracture in patients with low back pain. J Clin Epidemiol. 2008;61(2):110-8.

13. Smidt N, Rutjes AW, van der Windt DA, Ostelo RW, Reitsma JB, Bossuyt PM, et al. Quality of reporting of diagnostic accuracy studies. Radiology. 2005;235(2):347-53.

14. Groenwold RH, Van Deursen AM, Hoes AW, Hak E. Poor quality of reporting confounding bias in observational intervention studies: a systematic review. Ann Epidemiol. 2008;18(10):746-51.

15. Moseley AM, Herbert RD, Maher CG, Sherrington C, Elkins MR. PEDro scale can only rate what papers report. Aust J Physiother. 2008;54(4):288.

16. Jüni $P$, Altman DG, Egger M. Systematic reviews in health care: Assessing the quality of controlled clinical trials. BMJ. 2001;323(7303):42-6.

17. Hopewell S, Dutton S, Yu LM, Chan AW, Altman DG. The quality of reports of randomised trials in 2000 and 2006: comparative study of articles indexed in PubMed. BMJ. 2010;340:c723.

18. DerSimonian R, Charette LJ, McPeek B, Mosteller F. Reporting on methods in clinical trials. $N$ Engl J Med. 1982;306(22):1332-7.

19. Equator Network. Enhancing the quality and transparency of health research. 2011 [cited 2011 25/04/2011]; Available from: http://www.equator-network.org/home/.

20. Simera I, Moher D, Hirst A, Hoey J, Schulz KF, Altman DG. Transparent and accurate reporting increases reliability, utility, and impact of your research: reporting guidelines and the EQUATOR Network. BMC Med. 2010;8:24.

21. Schulz KF, Altman DG, Moher D; CONSORT Group. CONSORT 2010 statement: updated guidelines for reporting parallel group randomized trials. Ann Intern Med. 2010;152(11):726-32.

22. Begg C, Cho M, Eastwood S, Horton R, Moher D, Olkin I, et al. Improving the quality of reporting of randomized controlled trials. The CONSORT statement. JAMA. 1996;276(8):637-9

23. Moher D, Hopewell S, Schulz KF, Montori V, Gøtzsche PC, Devereaux PJ, et al. CONSORT 2010 explanation and elaboration: updated guidelines for reporting parallel group randomised trials. J Clin Epidemiol. 2010;63(8):e1-37.

24. Costa LO, Maher CG, Moseley AM, Sherrington C, Herbert RD, Elkins MR. Editorial: Endorsement of trial registration and the CONSORT statement by the Revista Brasileira de Fisioterapia. Rev Bras Fisioter. 2010;14(3):v-vi.

25. Clarke M. The QUORUM statement. Lancet. 2000;355(9205):756-7.

26. Pengel LHM, Herbert RD, Maher CG, Refshauge KM. Acute low back pain: systematic review of its prognosis. BMJ. 2003;327(7410):323

27. Hancock MJ, Maher CG, Latimer J, Spindler MF, McAuley JH, Laslett M, et al. Systematic review of tests to identify the disc, SIJ or facet joint as the source of low back pain. Eur Spine J. 2007;16(10):1539-50.

28. Costa LCM, Maher CG, McAuley JH, Costa LOP. Systematic review of cross-cultural adaptations of McGill Pain Questionnaire reveals a paucity of clinimetric testing. J Clin Epidemiol. 2009;62(9):934-43

29. Costa LOP, Maher CG, Latimer J, Smeets RJEM. Reproducibility of rehabilitative ultrasound imaging for the measurement of abdominal muscle activity: a systematic review. Phys Ther. 2009;89(8):756-69.

30. Maher C. PRISMA: helping to deliver information that physical therapists need. Phys Ther 2009;89(9):870-2.

31. Liberati A, Altman DG, Tetzlaff J, Mulrow C, Gøtzsche PC, Ioannidis JPA, et al. The PRISMA statement for reporting systematic reviews and meta-analyses of studies that evaluate healthcare interventions: explanation and elaboration. BMJ. 2009;339:b2700.

32. Kocak FU, Unver B, Karatosun V. Level of evidence in four selected rehabilitation journals. Arch Phys Med Rehabil. 2011;92(2):299-303.

33. Grobbee DE, Hoes AW. Clinical epidemiology. Principles, methods and applications for clinical research. Sudbury, Massachusetts: Jones and Bartlett Publishers; 2009

34. von Elm E, Altman DG, Egger M, Pocock SJ, Gøtzsche PC, Vandenbroucke JP, et al. The Strengthening the Reporting of Observational Studies in Epidemiology (STROBE) statement: guidelines for reporting observational studies. J Clin Epidemiol. 2008;61(4):344-9.

35. Bossuyt PM, Reitsma JB, Bruns DE, Gatsonis CA, Glasziou PP, Irwig LM, et al. The STARD statement for reporting studies of diagnostic accuracy: explanation and elaboration. Ann Intern Med. 2003;138(1):W1-12.

36. Smidt N, Rutjes AW, van der Windt DA, Ostelo RW, Bossuyt PM, Reitsma JB, et al. The quality of diagnostic accuracy studies since the STARD statement: has it improved? Neurology. 2006;67(5):792-7.

37. Costa LOP, Moseley AM, Sherrington C, Maher CG, Herbert RD, Elkins MR. Core journals that publish clinical trials of physical therapy interventions. Phys Ther. 2010;90(11):1631-40. 